\title{
Dynamic response analysis of DFB fibre lasers
}

\section{Yujun, Qian; Varming, Poul; Povlsen, Jørn Hedegaard; Lauridsen, Vibeke Claudia}

\section{Published in:}

Proceedings of the 24th European Conference on Optical Communication

Link to article, DOI:

10.1109/ECOC.1998.732476

Publication date:

1998

Document Version

Publisher's PDF, also known as Version of record

Link back to DTU Orbit

Citation (APA):

Yujun, Q., Varming, P., Povlsen, J. H., \& Lauridsen, V. C. (1998). Dynamic response analysis of DFB fibre lasers. In Proceedings of the 24th European Conference on Optical Communication (Vol. Volume 1, pp. 147148). IEEE. https://doi.org/10.1109/ECOC.1998.732476

\section{General rights}

Copyright and moral rights for the publications made accessible in the public portal are retained by the authors and/or other copyright owners and it is a condition of accessing publications that users recognise and abide by the legal requirements associated with these rights.

- Users may download and print one copy of any publication from the public portal for the purpose of private study or research.

- You may not further distribute the material or use it for any profit-making activity or commercial gain

- You may freely distribute the URL identifying the publication in the public portal 


\title{
DYNAMIC RESPONSE ANALYSIS OF DFB FIBRE LASERS
}

\author{
Qian Yujun, Poul Varming, Jørn Hedegaard Povlsen, Vibeke C. Lauridsen
}

Dept. of Electromagnetic Systems, Technical Univ. of Denmark, Building 348, DK-2800 Lyngby, Denmark

E-mail: qy@emi.dtu.dk

Abstract: We present a model for relative intensity noise (RIN) in DFB fibre lasers which predicts measured characteristics accurately. Calculation results implies that the RIN decreases rapidly with stronger Bragg grating and higher pump power

\section{Introduction}

In order to improve the stability of DFB fibre lasers [1] it is important to understand the dynamic behaviour in the presence of pump power fluctuations. The laser design can then be optimised to suppress relaxation oscillations around the peak of the RIN spectrum. Relaxation oscillations in FabryPerot fibre lasers have been analysed using two coupled rate equations [2]. This approach is not appropriate for DFB fibre lasers due to the presence of strong spatial holeburning similar to semiconductor DFB lasers [3]. The dynamic behaviour of semiconductor DFB lasers has been studied using complex models such as the CLADISS [4] model, which combines coupled-mode theory with the rate equations. We propose here a simplified model based on three spatially independent rate equations to describe the dynamic response of erbium doped DFB fibre lasers on pump power fluctuations, using coupled-mode theory to calculate the steady-state hole-burning of the erbium ion inversion.

\section{Model and equations}

The conventional rate equations for DFB fibre lasers are as:

$\frac{\partial x}{\partial t}=\frac{c}{n_{e f f}}\left(\Gamma_{s} \sigma_{g, s} n_{s}+\Gamma_{p} \sigma_{g, p} n_{p}\right)-\frac{x}{\tau_{21}} \equiv F(z, t)$

$\frac{\partial n_{s}^{ \pm}}{\partial t}=-\frac{c \Gamma_{s} \sigma_{g, s} n_{s}^{ \pm} \rho}{n_{e f f}}-\frac{c}{n_{e f f}}-\frac{\partial n_{s}^{ \pm}}{\partial z}$

$n_{s}=n_{s}^{+}+n_{s}^{-}=\frac{p_{\text {out }} n_{e f f}}{h v_{s} A_{e f f} c}, n_{p}=\frac{p_{\text {pump }} n_{e f f}}{h v_{p} A_{e f f} c}, x=\frac{N_{2}}{N_{1}+N_{2}}=\frac{N_{2}}{\rho}$

$\sigma_{g, s}=\sigma_{a, s}-\left(\sigma_{a, s}+\sigma_{e, s}\right) x, \sigma_{g, p}=\sigma_{a, p}-\left(\sigma_{a, p}+\sigma_{e, p}\right) x$

where subscript ' $s$ ' is referred to signal, ' $p$ ' to pump, ' $a$ ' to absorption, ' $e$ ' to emission, ' $g$ ' to gain, and the lower and upper laser level population is denoted ' $N_{i}$ ' and ' $N_{2}$, respectively. ' $\sigma$ ' is the $E r^{3+}$-ion cross-section, ' $T$ the fibre confinement factor, ' $x$ ' the $\mathrm{Er}^{3+}$-ion inversion, ' $n$ ' the photon density, ' $v$ ' the light frequency in vacuum and ' $\rho$ ' is the $\mathrm{Er}^{3+}$-ion concentration. Further $n_{\text {eff }}$ denotes the effective refractive index, $A_{\text {eff }}$ the effective area of the fibre core, $\tau_{21}$ the laser upper level lifetime, $p_{\text {out }}$ the output laser power,

$p_{\text {pump }}$ the pump power, $c$ the speed of light in vacuum and $h$ the Planck's constant. $n_{s}{ }^{+}$and $n_{s}{ }^{-}$are the signal photon densities in the positive and negative directions, respectively.

The spatial distribution of the inversion, pump photon density and signal photon density is described using the envelope functions $f_{x}, f_{p}$ and $f_{s}$, respectively, while ' $\alpha$ ' and ' $\varepsilon$ ' describes the temporal variation of the inversion and power, respectively:

$$
\begin{aligned}
& x(z, t)=x_{0} f_{x}(z)+\alpha_{s}(t) x_{s}(z)+\alpha_{p}(t) x_{p}(z) \\
& n_{s}^{ \pm}(z, t)=n_{s 0}\left(1+\varepsilon_{s}(t)\right) f_{s}^{ \pm}(z), n_{p}(z, t)=n_{p 0}\left(1+\varepsilon_{p}(t)\right) f_{p}(z) \\
& x_{s}(z)=n_{s 0} \frac{\partial x(z)}{\partial n_{s 0}}, x_{p}(z)=n_{p 0} \frac{\partial x(z)}{\partial n_{p 0}}
\end{aligned}
$$

The envelope functions $f_{x}, f_{p}$ and $f_{s} \equiv f_{s}^{+}+f_{s}^{*}$, the average photon densities $n_{s 0}$ and $n_{p 0}$, and the average inversion $x_{0}$ is calculated from the steady-state coupled-mode theory [5]. The spatially independent rate equations are obtained by integrating the rate equations over the entire cavity length $L$, using the continuity conditions:

$$
f_{s}^{-}(0)=f_{s}(0), f_{s}^{+}(L)=f_{s}(L), f_{s}^{+}(0)=f_{s}^{-}(L)=0
$$

Using the integral notation $\langle f\rangle$, we can normalise the envelope functions $f_{x}, f_{p}$ and $f_{s}$ as follows:

$$
\langle f\rangle=\frac{1}{L} \int_{0}^{L} f(z, t) d z,\left\langle f_{x}\right\rangle=\left\langle f_{s}\right\rangle=\left\langle f_{n}\right\rangle \equiv 1
$$

The new simplified and spatially independent rate equations for DFB fibre lasers are deduced as follows:

$$
\begin{aligned}
& \frac{d \alpha_{s}}{d t}=\frac{\left\langle F \cdot x_{s}\right\rangle \cdot\left\langle x_{p}^{2}\right\rangle-\left\langle F \cdot x_{p}\right\rangle \cdot\left\langle x_{s} \cdot x_{p}\right\rangle}{\left\langle x_{s}^{2}\right\rangle \cdot\left\langle x_{p}^{2}\right\rangle-\left\langle x_{s} \cdot x_{p}\right\rangle^{2}} \\
& \frac{d \alpha_{p}}{d t}=\frac{\left\langle F \cdot x_{p}\right\rangle \cdot\left\langle x_{s}^{2}\right\rangle-\left\langle F \cdot x_{s}\right\rangle \cdot\left\langle x_{s} \cdot x_{p}\right\rangle}{\left\langle x_{s}^{2}\right\rangle \cdot\left\langle x_{p}^{2}\right\rangle-\left\langle x_{s} \cdot x_{p}\right\rangle^{2}} \\
& \frac{d \varepsilon_{s}}{d t}=-\frac{c\left(1+\varepsilon_{s}\right)}{n_{e f f}}\left\{A_{s}+\frac{f_{s}(0)+f_{s}(L)}{L}+\Gamma_{s} \rho\left\langle\sigma_{g s} \cdot f_{s}\right\rangle\right\} \\
& A_{s}=-\left(\sigma_{c, s}+\sigma_{e s s}\right) \Gamma_{s} \rho\left\{\alpha_{s}\left\langle x_{s}^{2}\right\rangle+\alpha_{p}\left\langle x_{s} \cdot x_{p}\right\rangle\right\}
\end{aligned}
$$

Relative intensity noise of DFB fibre laser $\left(\right.$ RIN $\left._{\text {laser }}\right)$ is defined as $R I N_{\text {taser }}=\left\langle\Delta p_{\text {out }}^{2}\right\rangle / p_{\text {out } 0}^{2}\left(H z^{-l}\right)$, where $\left\langle\Delta p_{\text {out }}^{2}\right\rangle$ is the mean-square output laser power fluctuation (in a $1 \mathrm{~Hz}$ bandwidth) at a specified frequency and $p_{\text {our }}$ the average output power. The relative noise $(R N)$ is defined as: $R N=$ $\operatorname{RIN}_{\text {laser }} / \operatorname{RIN}_{\text {pumpy }}$. The measured system noise $\left(R I N_{s y s}\right)$ includes $R I N_{\text {laser }}$ plus thermal noise and shot noise in the receiver.

For simplicity, a white noise spectrum is assumed for the pump source with constant amplitude $\delta$ over the entire frequency range, which is in reasonable agreement with measurement of the pump spectrum.

\section{Results and discussion}

Parameters used in calculations, unless otherwise specified, are: $\quad \rho=1.7 \cdot 10^{25} \mathrm{~m}^{-3}, \quad \tau_{2 \jmath}=10^{-2} \mathrm{~s}, \quad \sigma_{a, s}=1.85 \cdot 10^{-2.5} \mathrm{~m}^{2}$, 
$\sigma_{a, p}=2.08 \cdot 10^{-25} \mathrm{~m}^{2}, \quad \sigma_{e, s}=3.38 \cdot 10^{-25} \mathrm{~m}^{2}, \quad \sigma_{e, p}=0.72 \cdot 10^{-25} \mathrm{~m}^{2}$, $A_{e f f}=1.256 \cdot 10^{-11} \mathrm{~m}^{2}, \quad \Gamma_{s}=0.77, \Gamma_{p}=0.79, \quad \delta=10^{-4}, \quad L=0.05 \mathrm{~m}$, $n_{\text {eff }}=1.45, p_{\text {pumpo }}=40 \mathrm{~mW}$. The coupled-mode calculations use a Bragg grating with coupling coefficient $\kappa$ and a $4 \mathrm{~mm}$ long distributed $\pi$ phase-shift at the centre, pump wavelength $1480 \mathrm{~nm}$ and lasing wavelength $1560 \mathrm{~nm}$. All variables are initialised to the unperturbed steady-state solutions in calculations. The non-uniformity parameter $\sigma_{2}$ introduced in [3] can be calculated as the spatial variation of $f_{s}$ : $\sigma_{2} \equiv\left\langle f_{s}^{2}\right\rangle-1$.

Fig.1 shows that the relaxation frequency will be lower with higher grating coupling coefficient, which is the same as predicted for semiconductor lasers [3], and also lower with lower $\mathrm{Er}^{3+}$-ion concentration. Further, the non-uniformity factor $\sigma_{2}$ increases and relative noise peak decreases with stronger grating, but they keep almostly constant with different $\mathrm{Er}^{3+}$-ion concentrations. This is different from the highly concentration dependent noise characteristics in Fabry-Perot fibre lasers [2].

Fig. 1: Calculated variations of peak relative noise $(\mathrm{RN})$, relaxation frequency $f_{r}$ and non-uniformity factor $\sigma_{2}$ with $<\mathrm{a}>$ coupling coefficient $\kappa\left(\rho=1.18 \cdot 10^{25} \mathrm{~m}^{-3}\right)$ and $<\mathrm{b}>\mathrm{Er}^{3+}$. ion concentration $\rho\left(\kappa=130 m^{-1}\right)$
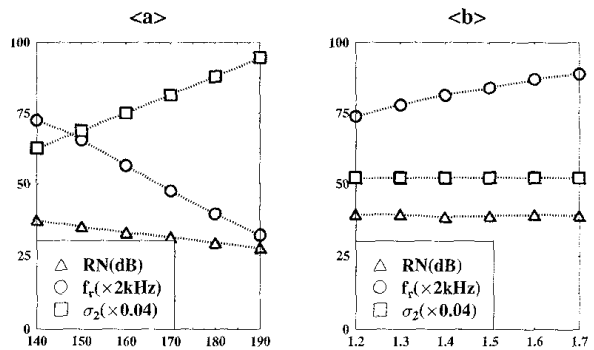

Coupling Coefficient $\kappa\left(\mathbf{m}^{-1}\right) \quad \mathbf{E r}^{3+}$ Concentration $\rho\left(\times 10^{25} \mathbf{m}^{-3}\right)$

Fig. 2: Calculated and measured system relative noise $\left(\mathbf{R N}_{\text {sys }}\right)$ spectrums with $40 \mathrm{~mW}$ pumping

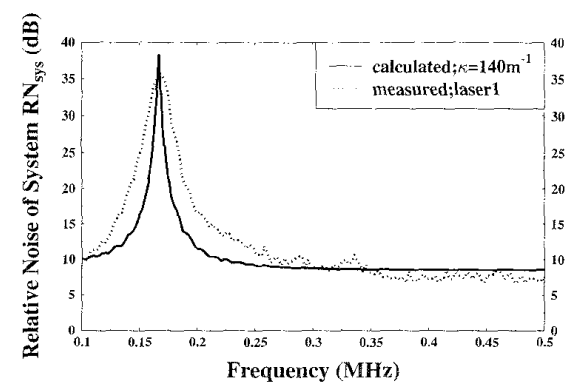

Fig. 2 shows good agreement between the calculated and measured system relative noise $R N_{s y s}$ spectrums. The width of the measured noise peak is broader than the calculated, which may be due to the $10 \mathrm{kHz}$ resolution bandwidth of the measurement. In the calculation, it is supposed that the thermal noise is constant and dominates the system noise far from the noise peak.
The comparison between calculated and measured results for noise characteristics related to the coupling coefficient and the pump power are shown in Fig.3. When the pump power increases, the peak noise decreases, while the relaxation oscillation frequency increases.

Fig. 3: Calculated and measured variations of $<a>$ peak relative noise $R N$ and $<b>$ relaxation frequency $f_{r}$ with pump powers $\mathbf{p}_{\text {pumpo }}$

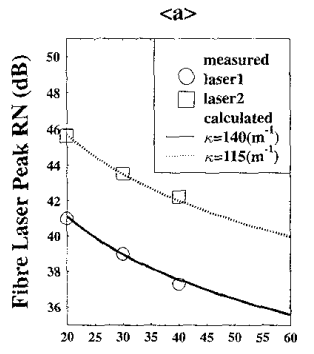

Pump Power $\mathbf{p}_{\text {pumpo }}(\mathrm{mW})$

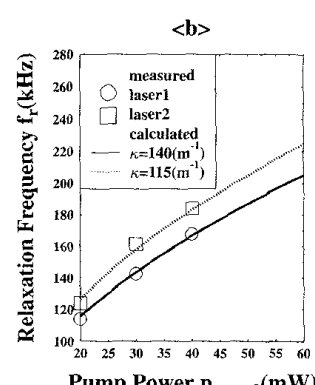

Pump Power $\mathrm{p}_{\text {pumpo }}(\mathrm{mW})$
Calculations also indicate that with moderate pump power fluctuation $(\delta<1 \%)$, the laser relative noise peak $(\mathrm{RN})$ is independent on the fluctuation magnitude $\delta$. To keep pump fluctuation as low as possible is always the most effective way of reducing laser noise, e.g., by introducing a negative feedback to the pump [6].

In conclusion, the simplified, spatially-independent rate equations considering the hole-burning effect are presented here to describe the dynamic response of DFB fibre lasers, especially the relative intensity noise characteristics due to pump power fluctuation. It implies efficient noise reduction using stronger Bragg grating, higher pump power and lower pump fluctuation.

\section{References}

11/ J. Hübner, P. Varming and M. Kristensen, Five Wavelength DFB Fibre Laser Source for WDM Systems, Electron. Lett., 1997, Vol. 28, pp. 139-140.

12/ Ming Ding and Peter K. Cheo, Analysis of Er-doped Fibre Laser Stability by Suppressing Relaxation Oscillation, IEEE Photon. Technol. Lett., 1996, Vol. 8, No. 9, pp. 1151-1153.

/3/ Junichi Kinoshita, Modeling of High-speed DFB Lasers Considering the Spatial Hole-burning Effect Using Three Rate Equations, IEEE Photon. Technol. Lett. 1994, Vol. 30, No. 4, pp. 929-938.

14/ P. Vankwikelberge, G. Morthier and R. Baets, CLADISS-A Longitudinal Multimode Model for the Analysis of the Static, Dynamic, and Stochastic Behaviour of Diode Lasers with Distributed Feedback, IEEE J. Quantum Electron., 1990, Vol. 26, No. 2, pp. 1728-1741.

15/ V. C. Lauridsen, T. Søndergaard, P. Varming and J. H. Povisen, Design of distributed feedback fibre lasers, in IOOC/ECOC'97 Technical Digest, Vol. 3, pp. 39-42.

161 G. A. Ball, G. Hull-Allen, C. Holton and W. W. Morey, Low Noise Single frequency Linear Fibre Laser, Electron. Lett., 1993, Vol. 29, No. 18, pp. 1623-1625. 